\title{
Unpacking conceptual elements of smart learning in the Korean scholarly discourse

\author{
Kiran Budhrani ${ }^{{ }^{*}}$ (D), Yaeeun $\mathrm{Ji}^{2}$ and Jae Hoon Lim²
}

\footnotetext{
* Correspondence: kbudhran@uncc. edu

${ }^{1}$ Center for Teaching and Learning, University of North Carolina at Charlotte, 9201 University City Blvd, Charlotte, NC 28223, USA Full list of author information is available at the end of the article
}

\begin{abstract}
This study is a descriptive content analysis of "smart learning" as defined and conceptualized by Korean educational researchers from 2010 to 2018. The purpose of research is to examine the smart learning literature for the core conceptual elements that ran through the scholarly discourse of "smart learning" in South Korea; to understand how the three elements of smart learning environment, pedagogy, and learner, are represented in those definitions and elucidate some notable trends in its conceptual development throughout the years.

We utilized Google Scholar, Korean Citation Index, and RISS to collect relevant scholarly publications written in Korean and English text. We identified 37 publications that included either an explicitly stated definition of smart learning or included a quality statement that clearly describes what constitutes smart learning. We initially used an inductive coding technique and identified repeated keywords among the definitions of "smart learning." Later we applied the three elements of smart learning to draw further interpretations.

Our data analysis generated five major themes: (1) Smart learning environments is a dominating element in the discourse; (2) Enriched conceptual exploration of smart learning pedagogies; (3) Dwindling interest in smart learners; (4) Conceptual ambiguity lingers in the smart learning discourse; (5) Paths of discoursal development vary across the three domains of smart learning. We conclude that our findings offer an important insight to the Korean and international scholarly discourse on the current dynamics of three essential elements of smart learning.
\end{abstract}

Keywords: Smart learning, Smart learning elements, South Korea, Smart learning definition, Content analysis, Textual analysis, Smart learning environments, Smart pedagogy, Smart learners

\section{Introduction}

Technological revolution is dramatically changing all sectors of society; education is not an exception. The fast proliferation of smart devices, smart systems, and smart technologies has facilitated new approaches for learners, learning technologies, learning processes, and learning strategies, creating an emerging research area called 'smart learning' (Uskov et al. 2015). In some countries, smart learning has driven educational reforms and innovation. For example, Singapore implemented the Intelligent Nation (iN2015) master plan in 2006 (Hua 2012); Malaysia implemented a smart education project and had its Malaysian Smart School Implementation Plan in 1997 (Ong 2006). In 2011, South Korea (hereinafter referred to as "Korea") implemented the smart

(c) The Author(s). 2018 Open Access This article is distributed under the terms of the Creative Commons Attribution 4.0 International License (http://creativecommons.org/licenses/by/4.0/), which permits unrestricted use, distribution, and reproduction in any medium, provided you give appropriate credit to the original author(s) and the source, provide a link to the Creative Commons license, and indicate if changes were made. 
learning strategy, envisioning "an intelligent, customized learning system for fostering 21st century skills" (MEST and KERIS 2011, p. 17).

South Korea is one of leading countries in the adoption of Information and Communications Technology (ICT), mobile devices, Internet connection speed, and infrastructure (Statista 2016). With Korea being at the forefront of broadband access, ICT, and mobile technology, educational policies and programs are largely interrelated with integrating technology (Gallagher 2016). The Korean Ministry of Education has continuously contributed much attention and support towards the improvement of ICT infrastructure in education to provide a high-quality educational environment to students with abundant resources on teaching and learning. In fact, Korea is known as one of the first few Asian countries where the central government initiated mart learning project, which was immediately followed by a series of enriched discussion among educational researchers in the country. According to Duran-Sanchez et al. (2018), there are more scholars from Korea who write about smart learning than other countries such as China, India, Canada, and the United States. The country presents a unique context to explore the conceptual development of smart learning because for them, smart learning is more than a scholarly concept; it is a concept well positioned within a government policy or master plan for advancing technology-supported educational initiatives nationwide.

The International Association of Smart Learning Environments (IASLE) provides a highly eclectic definition of smart learning as "an emerging area alongside other related emerging areas such as smart technology, smart teaching, smart education, smart-e-learning, smart classrooms, smart universities, smart society" (IASLE 2018, para. 1). Some researchers claim smart learning is a new field of research (Hoel and Mason 2018); others contest it is a new concept of learning (Hwang 2014; Kim et al. 2013); several point out that it is a new educational paradigm (Duran-Sanchez et al. 2018; Kim et al. 2011; Lee et al. 2014; Zhu et al. 2016); while some refer to it as a phenomenon (Tikhomirov et al. 2015). Tikhomirov et al. (2015) describes smart learning as an ambiguous new trend with different interpretations, thus causing "conceptual uncertainty" (p. 48) and making it difficult to understand its peculiarities. While new generations of learners will require an education system that attends to developing smarter learning environments and technologies, smarter pedagogies, and smarter learners, researchers in the field have shown greatly varied perspectives and research interests.

Despite several attempts made by researchers, there is no clear definition on the concept of 'smart learning' (Duran-Sanchez et al. 2018; Kim et al. 2013; Lee et al. 2013; Lee et al. 2015; Sung 2015). The purpose of this study is to examine the concept of 'smart learning' in the Korean scholarly community from 2010 to 2018 and to elucidate notable trends in its conceptual development. The following research questions are posed:

1. To what extent are the three elements of smart learning--smart environment, pedagogy, and learners--represented and described among Korean scholars?

2. How is smart learning conceptualized by Korean scholars?

3. What trends are present in South Korea's scholarly discussion on smart learning from 2010 to 2018 ? 
Globally, researchers use multiple terms, such as smart learning, smart education, and smart learning environments, interchangeably. In this paper, we will utilize the term 'smart learing', simply to avoid unnecessary redundancy and to ensure consistency throughout the paper.

\section{Literature Review}

Smart learning un/defined

The conceptual uncertainty (Tikhomirov et al. 2015) of smart learning comes forth from the varying perspectives researchers have taken to define smart learning. From our synthesis of the literature on smart learning definitions, we explain three perspectives.

In the first perspective, researchers define smart learning with emphasis on the 'smarter technologies' necessary to facilitate new pedagogies, ultimately, developing better learners and producing higher learning outcomes. For example, Zhu and He (2012) state that the essence of smart learning is "to create intelligent environments by using smart technologies, so that smart pedagogies can be facilitated as to provide personalized learning services and empower learners" (p. 6). Hwang (2014) explains that smart learning systems can provide learning guidance, hints, supportive tools, or learning suggestions just-in-time. Kwak (2010) defines smart learning as a learning system that provides easy access to learning sources and enhances interaction among learners and the instructor.

However, as a second perspective, researchers conceptualize smart learning with greater emphasis is on developing a 'smarter learner', one who can integrate smart learning environments into their learning and develop twenty-first century skill sets such as critical thinking, communication, collaboration, and creativity (P21 2007). MEST and KERIS (2011) defines smart learning as "an education system designed to strengthen the capabilities of 21st century's learners by offering an intelligent and customized learning solution" (p. 12). Additionally, Duran-Sanchez et al. (2018) describes "the objective of smart learning is to improve the learning quality and student outcomes throughout the student's educational process; it focuses on contextual, personalized and transparent learning capable of encouraging the emergence of students' intelligence and facilitating their ability to solve problems in real environments; students are provided with personalized education where they can learn flexibly, in any place and at any time, and work collaboratively" (p. 2).

Kinshuk et al. (2016) applies a third perspective focusing on 'smarter pedagogies,' stating that smart learning goes beyond the technology; when learning environments make effective use of advanced smart technologies, teaching methods and learning strategies must adapt and change. In this light, some researchers define smart learning emphasizing new pedagogies needed for learners to effectively integrate technology. For example, Sung (2015) describes smart learning to be "a humanistic approach to learning that offers hands-on and personalized opportunities to acquire information, manage knowledge, interact, and collaborate with peers and instructors so that learners can apply their knowledge and skills to solve problems and achieve goals in an authentic context" (p. 116). Noh et al. (2011) explain that smart learning is a human-centered and self-directed learning method which provides convenient access to information for learning, integrates learning activities with smart information and communication technology (ICT), and effectively supports interactions among learners, as well as between 
instructors and learners. Kinshuk et al. (2016) describe smart learning environments to provide seamless, real-time, and ongoing evidence of change in student knowledge as they navigate both formal and informal learning contexts.

While smart learning should not be limited to just one perspective being either smart technologies, smart learners, or smart pedagogy, definitions tend to emphasize one perspective over the other. The scholarly research is quite mixed. Thus, several researchers have found consensus that there is no clear definition on the concept of smart learning (Duran-Sanchez et al. 2018; Jo et al. 2012; Kim et al. 2013; Lee et al. 2013; Lee et al. 2015; Sung 2015).

\section{Smart learning in Korea}

South Korea has been in the top three for the fifth consecutive year as one of the most prominent countries in the information technology sector, based on the Global ICT Development Index from the International Telecommunication Union (ITU). As of 2017, the overall ICT performance of Korea has ranked second place worldwide with high scores in three dimensions: the availability of ICT infrastructure (access), level of ICT usage, and the capability to use ICTs (skills) (ITU 2017). In addition, OECD (2018) reports that $99.5 \%$ of all households in Korea have access to the Internet. A survey conducted by Korea Internet \& Security Agency (KISA) showed that in 2017, more than 83.9\% of Korean children within age 3 to 9 kids are connected to the Internet; $99.7 \%$ of Koreans at age 10 to 40 are connected to the Internet; and $98.7 \%$ of Koreans in their 50 s are connected to the Internet. Approximately $90 \%$ of the population, starting at age six, individually possesses smart devices such as smartphone, tablet, and wearable device (KISA 2018). Koreans actively use the Internet not only in their daily lives such as social networking, shopping, and banking, but also in the public and private sectors.

With a strong passion for high-quality education and superior access to advanced, connected technologies, Korea has gained a significant attention from the international community for emerging educational trends in a highly connected society. In 2011, the Ministry of Education, Science \& Technology (MEST) in Korea launched SMART education as a paradigm shift to foster learners' capacities for twenty-first century by integrating various ICT into teaching and learning practices (MEST and KERIS 2011). MEST (2011) defined "SMART" as Self-directed, Motivated, Adaptive, Resource-enriched, and Technology-embedded learning methods. The smart learning initiative intended to reform the agenda of schools and educational policies. The reform was due to anticipated changes in the role of teachers and students, the advancement of teaching-learning methods amidst emerging educational environments, and the individualization and customization of learning to fit the various levels of learning need (MEST and KERIS 2011).

MEST and KERIS' (2011) definition of smart learning as five characteristics did not provide educators with details on how to implement it. The earlier concept of smart learning was proposed by Kwak (2010), which emphasized the individual learner over the technology and proposed that learning through such a technological infrastructure should be according to the learning needs of the individual (Gallagher 2016; Kim et al. 2013). Other researchers defined additional characteristics of smart learning to include self-directed, real-time, and personalized learning (Kim 2010, as cited in Sung 2015, p. 117). Jang (2010) defined smart learning to be learner-centered, collaborative, flexible, interactive, self-directed and realistic (as cited in Sung 2015, p. 116). 
Other definitions of smart learning traces back to how the concept emerged amidst similar terminologies like e-learning, m-learning, and u-learning. Noh (2011) claims that the concept of smart learning emerged as a response to the limitations of e-learning, as well as, a result of changes brought about by the advancement of smart devices and technologies. It is an "evolved form of e-learning that included smarter educational environments" generally making use of smart phones to enhance the effectiveness of education based on new learning methods (i.e., participation, sharing, and customization), new pedagogies, smarter content, and smart devices (Jo et al. 2012). While Korean scholars have attempted to define and describe smart learning and its characteristics, no clear definition of smart learning exists to date (Jo et al. 2012; Kim et al. 2011; Lee et al. 2013; Lee et al. 2015; Sung 2015).

\section{Theoretical Framework: Conceptual Elements of Smart Learning}

This study is grounded in Zhu et al.'s model of smart learning (2016) featuring three elements essential to smart learning: (1) smart learning environments, (2) smart pedagogies, and (3) smart learners. This model places the learner at the center of the framework and highlights that smart pedagogies and smart environments must support the development of smart learners. Zhu et al.'s framework has provided an analytic scheme for our initial content analysis and served as a ground for drawing more in-depth comparisons across the three categories. The following literature section is also structured according to the three essential elements of smart learning; each element is explained with a detailed and critical synthesis of existing literature on smart learning.

\section{Smart learning environments}

Zhu et al.'s framework (2016) emphasizes the supporting role that a technology-rich environment plays in supporting effective, efficient, and meaningful learning for learners. The authors describe such an environment to be learner-centric, a personalized and adaptive learning service, with interactive and collaborative tools, context-aware, and with ubiquitous access. While this element takes a supporting role for smart learners in Zhu et al.'s model, there is little doubt that emergence of smart environments with smart technologies has been the driving force for most smart learning initiatives around the globe.

Making learning systems smarter has been on the agenda of researchers since the 1980s (Hwang 2014). The concept of smart learning sprung from online learning concepts of e-learning, m-learning, and u-learning (Kim 2012; Kim et al. 2013; Lee and Son 2013; Lim 2012; Zhu et al. 2016). E-learning is electronically supported learning that uses information and communication technologies (ICT) to enable radio and broadcasting technology, computer-based instruction $(\mathrm{CBI})$ or web-based learning (Kim et al. 2013; Lee and Son 2013; Lim 2012). Mobile learning (m-Learning) was driven by the advancement of easy-to-use mobile devices and wireless networks (Kim et al. 2013). It improved e-learning by adding flexibility in learning time, location, and cost, as well as, mobility of the learner, which was not supported in traditional educational modes (Kim et al. 2013; Hwang 2014).

Ubiquitous or u-learning is a more high-tech learning environment that allows learning in real-time and real-world locations, within the context of the learner, utilizing advanced technologies like mobile devices (e.g., smartphones and tablet computers), wireless 
communication networks, sensing technologies (e.g., RFID, GPS and QR codes), augmented and virtual reality, and speech recognition technologies. Sensing technologies are key to achieve context-aware ubiquitous learning (Hwang et al. 2008). U-learning helps achieve the "4As" (anytime, anywhere, anything, and any place learning) (Liu et al. 2017) where learning can take place without the limitations of time, location, or environments. Hwang (2014) explains that u-learning environments differs from smart learning environments in that smart learning environments enables learners to access digital resources and interact with learning systems in any place and time, but also provides learning guidance, hints, supportive tools, or learning suggestions just-in-time and in the right form, similar to a "wise-friend." Similarly, Kinshuk et al. (2016) describes them as self-directed guided systems to help learners in their learning goals. Smart learning systems are promising in that it can guide learners to do the right thing in the right way at the right time and the right place, based on their real-world personal needs (Hwang 2014). More advanced learning environments include adaptive, intelligent tutoring systems, and ambient intelligent environments.

Smart learning environments aim to "promote better and faster learning" (Koper 2014, p. 1). They provide access to a wide range of resources and content, are context-aware (real-world, real-time sensing) in formal and informal settings, offers instant, adaptive, and personalized learning guidance (e.g., content, curriculum, strategy, support, feedback, hints), and adapts user interfaces and content via ubiquitous computing systems based on learner's needs (i.e., learner profiles, learning performance, learning behaviors) (Hwang 2014; Kinshuk et al. 2016; Koper 2014; Raghunath et al. 2018).

Smart learning technologies have several technology requirements to be successful such as learning management systems (Tikhomirov et al. 2015), high quality and usable smart devices (Yang et al. 2008), network infrastructure and sensors, cloud infrastructure (Raghunath et al. 2018), devices and data security (Gordon 2015), big data, historical datasets, and learning analytics (Kinshuk et al. 2016).

Researchers have defined that smart learning environments should have the following system features: mobility, context-awareness (i.e., location awareness, situation awareness, social awareness), adaptability, seamlessness, pervasiveness, integrity, interactivity, interoperability, and engagement (Klimova and Simonova 2015; Tikhomirov et al. 2015; Yang et al. 2008; Zhu et al. 2016). Kinshuk et al. (2016) explains that context-aware learning systems provide learners with authentic learning contexts and seamless learning experiences. These systems would assist teachers and instructors in direct monitoring of the learning environment, understand learners' conditions and give learners real-time adaptive assistance, while at the same time facilitating independent learning for the learners (Hwang 2014). Going beyond requirements and features, Derzko (2006) has developed "smartness maturity levels" to classify different smart learning systems; listed from least smart to more smart, systems should be able to adapt, sense, infer, learn, anticipate, and self-organize.

\section{Smart pedagogies}

Compared to m-learning or u-learning, which focus on the devices or Internet technologies, smart learning strongly emphasizes the pedagogy needed when integrating technology. Student feedback in Swallow (2015) highlights that current teaching methods lack innovation 
with respect to technology, and that it is necessary to define twenty-first century teaching methods that align to emerging technology and learning systems. In order to provide learners with a learning environment that makes effective use of technological advances, teaching methods and learning strategies also require changes (Kinshuk et al. 2016). Hwang (2014) notes that smart learning raises new pedagogical issues on technology integration, learning and assessment strategies, learning performance evaluation, and learning behavior and pattern analysis. Liu et al. (2017) and MEST and KERIS (2011) also emphasize the need to keep learners motivated, interested, and engaged in their learning process.

Zhu et al.'s framework (2016) suggests the use of deliberate instructional strategies to foster critical thinking and learning skills. The authors make the point that such high-level skills cannot be taught independently and must be taught within the context of where the learner is situated. Zhu et al. (2016) summarized four instructional strategies according to the number of persons involved in the learning activity: class-based differentiated instruction, group-based collaborative learning, individual-based personalized learning, and mass-based generative learning. Liu et al's framework (2017) on smart learning emphasizes that smart learning environments encompass rethinking pedagogical aspects such as learning goals, tasks, methods and strategies, media, resources, time and space of learning, feedback, learning communities, assessment, and support structures.

Smart learning promotes that curriculum must be redefined to promote deeper, challenging, motivating learning tasks, moving away from content mastery towards authentic, situated, real-world application. Educational programs should be individualized, flexible, and customized, creating a unique trajectory for each student (Tikhomirov et al. 2015). However, such tasks must be guided by specific and precise success criteria to help the student, the teacher, and the learning system know how well goals are being met, and to allow for appropriate formative and summative feedback. This implies there is a need to move beyond traditional forms of assessment, towards e-assessments, adaptive testing, and feedback methods that are personalized, automated, real-time, evidenced-based, and data-driven. Students can benefit from learning systems that can assess, monitor, and track their learning progress and provide guidance (i.e., feedback, hints) towards achieving their learning goals (Hwang 2014; Liu et al. 2017). For example, a study by Uzelac et al. (2015) used sensors to measure different aspects of the classroom environment (temperature, humidity and carbon dioxide levels) through sensors and attempted to link these factors to student focus. The lecturer wore a headset to collect data on the lecturer's voice and a microphone on a smartphone collected data on the overall noise level in the room. While the results of this study were preliminary, it showed that with sensors, strong analytical programs, and cloud storage, a "smart" classroom could exist that collects, analyzes, and packages data for teachers to use and improve the way they conduct instruction (Horowitz 2015).

Smart learning encourages high-level use of technology, utilizing it as a mindtool (Jonassen et al. 1998), or intellectual partner (Gros 2016) for collaboration, communication, and creation activities. Smart technologies must enable and accelerate social learning relationships between teachers and students, student with other students, and students with external learning partners such as mentors or tutors (Gros 2016). Such will provide students "multi-channel communication and intelligent learning support" (Liu et al. 2017, p. 34). 
Technology integration in smart learning environments is strongly centered on the use of mobile devices for seamless learning. The pedagogy of bring-your-own-device (BYOD) has gained interest in primary schools and higher education. Ng (2015) highlights an important aspect focused on the teacher and how they use smart phones as a pedagogical tool:

"Mobile devices blur the boundaries between formal (i.e. planned, structured, school-based and facilitated) and informal (unplanned, opportunistic, non-facilitated, out-of-school, interest / learner driven) learning, enabling continuity in learning between contexts; it is through the ability to use devices across contexts that seamless learning spaces are created." (Ng 2015, p. 8).

Mobile devices bring about new opportunities in the classroom such as: 1) increased visualization for students; 2) enhanced student presentation, discussion and focus; 3 ) efficient use of time-in-class; 4) increased student-student, student-teacher, student-technology, teacher-technology interaction, 5) relevant, up-to-date learning, and 6) the transfer of learning towards and outside of the classroom. If a smart learning environment is seamless, it supports all kinds of formal learning (learning within the school curriculum) and informal learning activities (i.e., social media, the Internet, MOOCs, game-based learning, etc.) to make learning easy, engaging, and effective (Duran-Sanchez et al. 2018; Liu et al. 2017). Seamless learning can be forged with the use of mobile and web apps in the classroom. Parmar (2016) points out that the role of the teacher in seamless learning does not fade away, but rather just becomes even more essential in the teaching learning process. However, there is strong emphasis on student-centered, self-directed learning where the student becomes his or her own teacher at some point. Seamless communication through digital channels allows the teacher and student to quite nicely become co-learners.

BYOD brings educational benefits if they are utilized in the learning environment with clear educational goals such (1) collaboration (i.e. peer assessment, peer-editing, brainstorming, shared notes, collaborative bookmarking, collaborative reading, class voting); (2) communication (i.e. posting comments, voice-calls, back-channeling, translation, sending reminders); and (3) creation (i.e. collaborative writing / blogging, mini-presentations, playlists, how-to guides) (Hardison 2013; Zhu et al. 2011). Mobile or web apps also allow activities for students to acquire information, make meaning, and promote knowledge transfer (Gikas and Grant 2013). Smart technology is instrumental in supporting seamless flipped classroom practice both inside and outside the classroom (Chiou et al. 2015).

\section{Smart learners}

Zhu et al.'s framework puts the student at the heart of smart learning and depicts that the goal of smart education is to foster a twenty-first century student with four levels of abilities: basic knowledge and core skills, comprehensive abilities, personalized expertise, and collective intelligence that will meet the needs of the work and life in the twenty-first century (2016). Similar discussions around smart learning and smart learning environments emphasize the need to develop smarter learners who can develop twenty-first century knowledge and skills to adapt to technological changes, meet the demands of the 
complex and diverse workplaces, and be successful to live, learn, and work in the digital age (Metiri Group and NCREL 2003).

The Korean government policy on smart learning explicitly states that smart education initiatives are expected to focus the education system to develop skills of twenty-first century learners, particularly the 7Cs of: critical thinking, problem solving, creativity and innovation, collaboration and leadership, cross-cultural understanding, communication, ICT literacy, and career and life skills (MEST and KERIS 2011). Many of these skills overlap with the overall vision of the partnership for twenty-first century (P21 2007) framework which proposes that students master: learning and innovation skills or the 4 Cs (i.e., critical thinking, communication, collaboration, creativity); information, media, and technology skills; and life and career skills (i.e., flexibility \& adaptability, initiative \& self-direction, social \& cross-cultural skills, productivity \& accountability, leadership \& responsibility).

Researchers around the world have presented similar trends that students should develop personalization, collaboration, communication, informal learning, productivity, and content creation skills (McLoughlin and Lee 2008; Redecker and Punie 2013). Tikhomirov et al. (2015) suggest that students must develop cognitive skills (i.e., self-organization, logical and analytical thinking, systems thinking, and critical thinking) and smart life skills (i.e., social skills, creativity, flexibility, and leadership). Similarly, Nerantzi and Beckingham (2014) identified the $5 \mathrm{Cs}$ of communicating, connecting, collaborating, creating, and curating to allow learners to engage in more complex teaching and learning activities with smart devices.

The smart era in South Korea peaked in 2012 with the establishment of a prototype Smart School in the city of Sejong (Hyun 2015), where students are experiencing high-tech learning experience, most of which students around the world can only dream of. At Sejong, all students have tablets with full wireless network and Internet coverage; there is automatic checking of attendance using an e-identification card; lectures from teachers are synchronized with students' tablets; students can review class material freely after school with their tablet and PC; notes on whiteboards are recorded for easy review; security systems check students' location; and teachers can check security status by area of the school (Lee n.d.). In such learning environments, learners must be self-directed, motivated to study, and responsible for their own work. With smart learning environments, they should be capable of accessing information, monitoring their learning progress, and seamlessly integrating technology into their study habits and day-to-day activities.

\section{Methodology}

\section{Research design}

This research employed a content analysis (Hsieh and Shannon 2005), a textual analysis method frequently used in social research to systematically reduce textual information and draw interpretations. In this study, we adopted the Smart Education framework of Zhu et al. (2016) presenting three key dimensions--smart learning environments, smart pedagogies, and smart learners, and utilized them as three predetermined theoretical categories. Our first analytic goal was to identify core conceptual elements that ran through the scholarly discourse of "smart learning" in South Korea and examine them in the light of Zhu et al.'s smart education theoretical framework. Further analysis 
aimed to illuminate notable patterns and dynamics in the smart learning discussion from 2010 to 2018, including the impact of government policy documents on the overall discoursal development.

\section{Data sources and data collection}

In content analysis, constructing a high quality, valid data set is pivotal to yielding accurate and meaningful interpretations in its analytic outcomes. The research team utilized three different methods to locate relevant scholarly publications that were most likely to include an explicit definition and/or thorough descriptions of "smart education/smart learning" by Korean scholars. We used Google Scholar to conduct the search for smart learning definitions. Keywords used for the search included "smart learning," "smart education," and "Korea/South Korea." Secondly, we conducted a literature search through Korean Citation Index (KCI), a premier academic search engine in South Korea, using exactly the same keywords (smart education, smart learning, Korea/South Korea). Both search engines listed results based on "relevance." A total of 212 resources were analyzed for the definition/description of "smart learning."

We established a clear set of criteria to determine the inclusion or exclusion of each source and the definition or description of "smart learning" presented. In order for a publication to be included in our database, the following criteria had to be met:

(1) The publication was through a publicly acknowledged outlet (journal articles, book chapters, conference papers or presentations, or official government reports).

(2) The publication was released between 2010 and 2018.

(3) The publication was written by Korean scholars in either English or Korean text.

(4) The publication presented one or more definitions or descriptions of smart learning.

(5) The definition or definition-like description had to be explicitly stated using phrases such as "smart education is...," "defined as...," "characterized by...," "constitutes...," "emphasizes...," or "is conceptualized as...".

Not surprisingly, almost all publications in our database listed the definitions/descriptions of "smart learning" in their Introduction or Literature Review section. We identified 37 sources in total from 2010 to 2018, majority of which were within 2011 to 2014 (Table 1), comprising journal articles, book chapters, conference papers or presentations, or official government reports included multiple definitions, each citing other prior publications/authors (Table 2).

We made significant effort to locate the cited primary source in multiple ways (e.g., a web search, other academic search engines, personal contact with the professional society/conference organizers and individual researchers) and replaced the secondary source with the primary source whenever available. If the primary source was not available, the definition (with an indirect citation reference) presented in the secondary source was classified as a secondary/rephrased definition. In some cases, we found that authors had significantly modified or revised the original definition while still citing the primary source. We classified these heavily modified/revised definitions as "modified/ revised definitions" and included them with the names of the secondary source author(s) followed by the primary source author(s). 
Table 1 Number of sources listed by year

\begin{tabular}{ll}
\hline Year & Frequency \\
\hline 2010 & 1 \\
2011 & 10 \\
2012 & 7 \\
2013 & 6 \\
2014 & 6 \\
2015 & 3 \\
2016 & 3 \\
2017 & 3 \\
2018 & 0 \\
Total & 1 \\
\hline
\end{tabular}

Tables 3 and 4 below show the number of primary and secondary sources in English and Korean as well as the number of primary source definitions and secondary modified revised and rephrased definitions. Among the total of 62 definitions, primary source definitions were 35 including 11 in English 24 in Korean; secondary modified/ revised or rephrased definitions were 27 with only two obtained from a Korean source.

\section{Data analysis}

Our database includes textual data in two different languages (English and Korean) inevitably posing a risk of mistranslation and cross-cultural misinterpretation. This is a common challenge in research conducted in cross-national, multilingual research contexts. While there is no panacea to this challenge, we addressed this challenge by (a) establishing a team of three researchers, each highly qualified to complete and collaborate on their assigned tasks, (b) setting up clear guidelines for key decisions, and (c) making a transparent decision based on the entire team's consensus. The first author and lead investigator established a set of guidelines to create the database while regularly consulting with a qualitative research expert (the third author). A bilingual Korean graduate student majoring in Teaching English as Second Language conducted a Korean literature search and completed the initial translation of Korean definitions/descriptions of "smart learning." The third author, a Korean transnational faculty, performed an expert review of the graduate student's translation work and checked each pair of Korean definitions and English translations to ensure consistency in terminology and expression across all 62 translated definitions/descriptions of smart learning. Once the quality of translation was confirmed, all definitions/descriptions were added to the database for coding.

The research team used a mixture of deductive and inductive coding techniques to analyze the 62 definitions of "smart learning." First, two members on the research team (the first and second authors) read each definition/description and identified a meaningful keyword (inductive coding) while determining if the keyword was about smart learning environment, pedagogy, or learner (deductive coding) according to Zhu et al.'s Smart Education framework. Each definition/description included multiple keywords. Each keyword was carefully examined by the two coders before being placed in one of the three given categories. The list of keywords/codes were repeatedly expanded and revised throughout the coding process in order to accommodate new keywords derived 
Table 2 Data sources listed by type, author, and frequency

\begin{tabular}{|c|c|c|}
\hline Source & Author & Frequency \\
\hline \multicolumn{3}{|l|}{ Journals } \\
\hline Asian Journal of Information Technology & Koo (2012) & 1 \\
\hline INFORMATION & Lee et al. (2015) & 1 \\
\hline International Journal of Smart Home & Lee et al. (2013) & 1 \\
\hline International Journal of Software Engineering and Its Applications & Lee and Son (2013) & 1 \\
\hline International Journal of u- and e-Service, Science and Technology & Jang (2014) & 1 \\
\hline Journal of Digital Convergence (디지털융복합연구) & $\begin{array}{l}\text { Kang (2011) } \\
\text { Noh et al. (2011) } \\
\text { Lee and Lee (2012) } \\
\text { Pyo et al. (2016) }\end{array}$ & 4 \\
\hline $\begin{array}{l}\text { Journal of Fisheries and Marine Sciences Education } \\
\text { (수산해양교육연구) }\end{array}$ & Han et al. (2014) & 1 \\
\hline $\begin{array}{l}\text { Journal of Internet Computing and Services } \\
\text { (인터넷정보학회논문지) }\end{array}$ & Kim (2014) & 1 \\
\hline $\begin{array}{l}\text { Journal of Korean Association for Educational } \\
\text { Information and Media (교육정보미디어연구) }\end{array}$ & $\begin{array}{l}\text { Leem and Kim (2013) } \\
\text { Leem, Lim, \& Sung (2014) }\end{array}$ & 3 \\
\hline $\begin{array}{l}\text { Journal of Korean Library and Information } \\
\text { Science Society (한국도서관 정보 학회지) }\end{array}$ & Lee, S.-G. (2013) & 1 \\
\hline Journal of Lifelong Learning Society (평생학습사회) & $\begin{array}{l}\text { Bang (2012) } \\
\text { Kwon and Bhang (2012) }\end{array}$ & 2 \\
\hline $\begin{array}{l}\text { Journal of Korea Academia-Industrial Cooperation Society } \\
\text { (한국산학기술학회논문지) }\end{array}$ & Cho (2018) & 1 \\
\hline $\begin{array}{l}\text { Journal of the Korea Society Industrial Information System } \\
\text { (한국산업정보학회논문지) }\end{array}$ & Shin and Kim (2011) & 1 \\
\hline $\begin{array}{l}\text { Journal of Korean Society for Internet Information } \\
\text { (인터넷정보학회논문지) }\end{array}$ & Meeyong Kim and Bae (2012) & 1 \\
\hline $\begin{array}{l}\text { Korea Information Processing Society Review } \\
\text { (정보처리학회지) }\end{array}$ & Lee (2013) & 1 \\
\hline Procedia - Social and Behavioral Sciences & Sung (2015) & 1 \\
\hline $\begin{array}{l}\text { The Journal of Korean Association of Computer Education } \\
\text { (컴퓨터교육학회 논문지) }\end{array}$ & $\operatorname{Lim}(2011)$ & 1 \\
\hline $\begin{array}{l}\text { The Journal of Special Children Education } \\
\text { (특수아동교육 연구) }\end{array}$ & Roh and Woo (2016) & 1 \\
\hline $\begin{array}{l}\text { The Journal of the Korea Contents Association } \\
\text { (한국콘텐츠학회 논문지) }\end{array}$ & Lee and Jin (2014) & 1 \\
\hline $\begin{array}{l}\text { The Korean Journal of Educational Methodology Studies } \\
\text { (교육방법연구) }\end{array}$ & Kang et al. (2012) & 1 \\
\hline $\begin{array}{l}\text { The Korean Journal of the Learning Sciences } \\
\text { (학습과학연구) }\end{array}$ & Hwang et al. (2011) & 1 \\
\hline \multicolumn{3}{|l|}{ Book Chapters } \\
\hline Information Technology and Management & $\begin{array}{l}\text { Jo, Park, Ji, Yang, } \\
\& \text { Lim (2016) }\end{array}$ & 1 \\
\hline Wireless Personal Communications & Jo, Park, Lee, \& Lim (2014) & 1 \\
\hline \multicolumn{3}{|l|}{ Conference Proceedings / Forum Presentation } \\
\hline Education Information Wednesday Forum & $\begin{array}{l}\text { Jang (2010) } \\
\text { Noh (2011) }\end{array}$ & 2 \\
\hline Free and Open Source Software Conference & $\begin{array}{l}\text { Kwon, Kim, Ryu, Kang, } \\
\text { Park, \& Joo (2013) }\end{array}$ & 1 \\
\hline International e-Learning Conference & Hwang (2011) & 1 \\
\hline
\end{tabular}


Table 2 Data sources listed by type, author, and frequency (Continued)

\begin{tabular}{lll}
\hline Source & Author & Frequency \\
\hline $\begin{array}{l}\text { Reports } \\
\text { Korea Education and Research Information Service (KERIS) }\end{array}$ & KERIS (2011) & 1 \\
Ministry of Education, Science and Technology (MEST) & MEST (2011) & 1 \\
$\begin{array}{l}\text { Ministry of Education, Science and Technology (MEST) } \\
\text { and Korea Education and Research Information Service (KERIS) }\end{array}$ & $\begin{array}{l}\text { MEST and KERIS } \\
\text { (2011, 2012) }\end{array}$ \\
\begin{tabular}{l} 
Total \\
\hline
\end{tabular}
\end{tabular}

from the definitions added to the data set later. The research team also merged some keywords/codes when they found it reasonable or even necessary.

At the end of this collaborative coding process, a total of 29 keywords were identified, where 11 keywords addressed smart learning environments, 9 keywords related to smart pedagogy, and 7 keywords associated with smart learners. Throughout the coding process, the two coders regularly met and discussed codebook development, consulted with the third author/qualitative methodologist, and exchanged questions so that they consistently applied any new or revised codes to all definitions. This first round of data analysis illuminated the overall landscape of conceptual ideas on smart learning and their total frequency over the 8 years of discussion.

The second stage of analysis further examined the chronological trend across the three domains of smart learning (learning environments, pedagogies, and learners), and compared and contrasted their discoursal dynamics over the given period. Special attention was given to four government policy documents (i.e. KERIS 2011; MEST 2011; MEST and KERIS 2011; MEST and KERIS 2012) and their release time in order to trace their impact on subsequent definitions of smart learning found in later publications. Once the conceptual breadth and frequency of keywords/codes and their chronological development patterns were all identified, the research team carefully reviewed the entire patterns and drew five major themes in order to address three research questions posed in the Introduction.

\section{Results}

Data analysis generated five major themes:

(1) Smart learning environments is a dominating element in the discourse

(2) Enriched conceptual exploration of smart learning pedagogies

(3) Dwindling interest in smart learners

(4) Conceptual ambiguity lingers in the smart learning discourse

(5) Paths of discoursal development vary across the three domains of smart learning

Table 3 Classification of data sources by primary and secondary source

\begin{tabular}{lc}
\hline Primary Sources in English Text & 10 \\
Primary Sources in Korean Text & 23 \\
Secondary Sources in English Text & $3(5)^{\text {a }}$ \\
Secondary Sources in Korean Text & 1 \\
Total & 37 \\
\hline
\end{tabular}

${ }^{a}$ Five sources included both the authors' own definition (primary source) and other scholars' definitions of smart learning (secondary source). These five sources were counted twice, once as a primary source and second as a secondary source. The total is the simple number of sources without double counting 
Table 4 Number of primary and secondary/modified definitions analyzed

\begin{tabular}{ll}
\hline Primary Definitions in English Text & 11 \\
Primary Definitions Korean Text & 24 \\
Secondary/Modified or Rephrased Definitions in English Text & 25 \\
Secondary/Modified or Rephrased Definitions Korean Text & 2 \\
Total & 62 \\
\hline
\end{tabular}

The first, second, and third themes address the first research question; the fourth theme addresses the second research question; and the fifth theme address the third research question.

\section{Smart learning environments is a dominating element in the discourse}

All three elements of smart learning were present in the 62 definitions of smart learning published between 2010 to 2018 by Korean scholars. Figure 1 shows the breakdown of the keywords that were coded for each element, based Zhu et al.'s (2016) smart learning framework. Our analysis shows that smart learning environment was the dominating element, with a total of 11 unique keywords coded; these were cited 134 times in the definitions. This frequency far exceeded those of smart pedagogies ( 9 unique keywords \& 94 citations in total) or smart learner keywords ( 7 unique keywords \& 46 citations in total).

Further analysis on the large number of smart learning environment codes yielded two mutually exclusive categories: (1) keywords describing the technology requirements for smart learning environments; and (2) keywords describing the system features of smart learning environments.

\section{Technology requirements for smart learning environments}

Two keywords describe the technology requirements for smart learning: smart technologies and social networks. A large number of Korean scholars' definitions (43 out of 62) mention the use of either a type of technology or device for smart learning. In fact, several scholars (e.g., Han et al. 2014; Kang 2011; Noh 2011) used the term "smart infra" in their definitions. Noh (2011) identified the need for cloud computing, networks, servers, smart devices, and embedded devices. Many other scholars mentioned the need for smartphones, mobile devices, tablets, advanced ICT, Internet, and wireless networks. All of these codes addressed the technology requirements needed for smart learning and were the most frequently cited keywords. The second keyword, social network, was also a technology requirement, yet we coded the use of social networks separately from the rest because several Korean scholars' definitions (KERIS 2011; Lee et al. 2013; Park 2011, as cited in Sung 2015) explicitly stated the use of social networks apart from a type of technology or device.

\section{System features of smart learning environments}

Nine of the eleven keywords coded to describe smart learning environments reflect technical features of a learning system. The nine keywords are: adaptive/customized (i.e., personalized, individualized, flexible, elastic), intelligent, ubiquitous (i.e., real-time, sensing), technology-embedded (i.e., integrated, convergent), having easy/convenient access, 


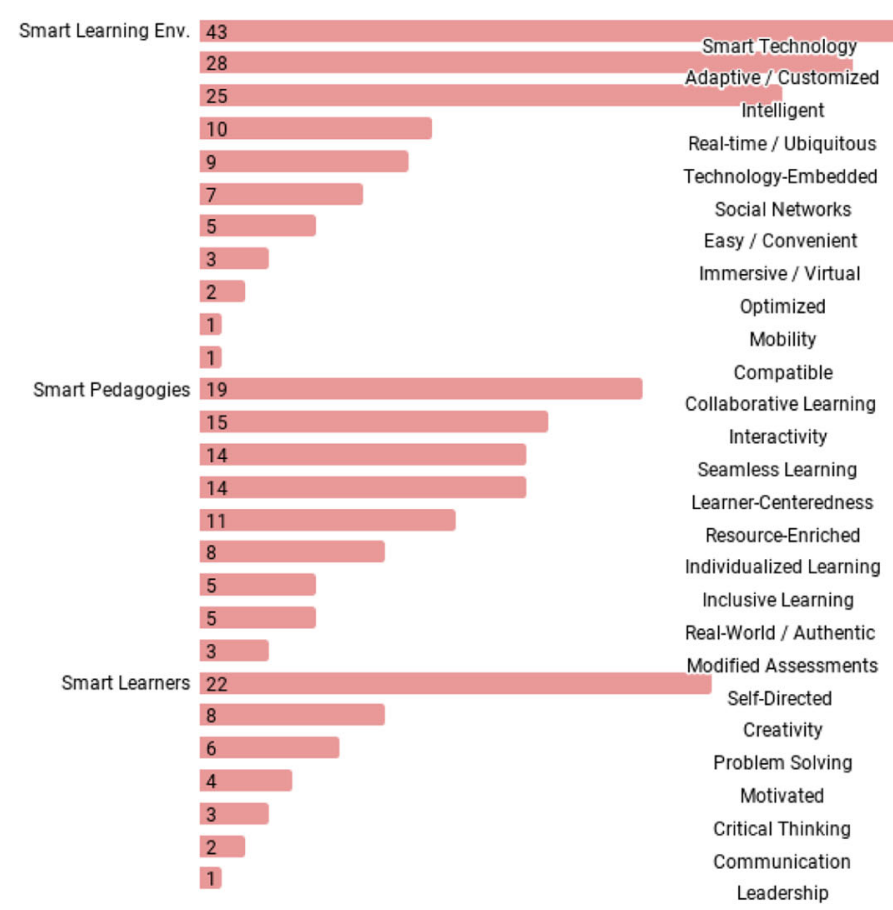

Fig. 1 Keyword breakdown by smart learning element

immersive (i.e., virtual, sense of reality), optimized, compatible, and mobility. Intelligent (cited 25 times) and adaptive/customized (cited 28 times) were the most frequently cited features. While no single definition included all nine features of smart learning system, most definitions stated at least two or more characteristics. This means that smart technology requirements, along with system features, was a focal point in Korean scholars' discussion.

\section{Enriched conceptual exploration of smart learning pedagogies}

Our analysis revealed nine keywords on smart pedagogies, cited 94 times across the 62 definitions (Fig. 1). Most keywords coded (7 out of 9) described a learning method such as: collaborative learning (i.e., cooperative learning, social learning, participation, collective intelligence), interactivity, learner-centeredness (i.e., learner-instructor interaction, learner-learner interaction, two-way communication), seamless learning (i.e., formal and informal settings, inside and outside the classroom), individualized/customized learning, inclusive learning (i.e., considers learner needs, styles, abilities, level, and aptitude), and real-world/authentic learning. However, learning methods were not the only concept described. Two other keywords surfaced the need for resource-enriched content (i.e., new forms of content, open and shared resources) and modified assessments.

Although this element had fewer keywords coded compared to smart learning environments, it presented a richer conceptual discourse than the other two elements. In fact, when coding, we aggregated a larger number of sub-codes for the smart pedagogies element compared to smart learning environments or smart learners. The 
statements in the definitions that described smart learning environments were shorter and clearer compared to the longer, murkier statements describing smart pedagogies.

The wide range of instructional/learning methods discussed among scholars imply that smart learning pedagogy does not promote a one-size-fits-all cookie-cutter approach. Rather it shows that Korean scholars engaged in rich conceptual exploration in order to identify appropriate pedagogical approaches for smart learning.

\section{Dwindling interest in smart learners}

While smart learning environments was clearly the dominating element in the smart learning discourse, it is also noteworthy that Korean scholars' early publications included a strong presence of the two other elements: smart pedagogies and smart learners in the beginning. From 2010 to 2011, there was a rather balanced distribution of the number of keywords emerging across the three smart learning elements (Fig. 2). Each element had a wide range of keywords represented, which attempted to form an early concept of smart learning. This, however, did not last long. By 2012, the concept of smart learning environments continued to expand with additional keywords, while the other two elements began to condense into fewer keywords.

Several early scholars (e.g., Kang 2011; Kwak 2010; Kwon and Bhang 2012; Lee 2010) of smart learning in Korea put emphasis on the learner. Kwak (as cited in Sung 2015, p. 116), for example, defined smart learning as an "intelligent and adaptive learning that considers many learning types and abilities and enables learners to foster thinking, communication, and problem-solving skills using various smart devices." However, keywords associated to smart learners plummeted by 2013, was no longer in the discourse by 2014 , and trailed along with slight visibility by 2018 . The only keyword that withstood the time span of 2010 to 2018 was 'self-directed.' While the government policies for smart learning (MEST and KERIS 2011, 2012) aimed to develop twenty-first century learners with the $7 \mathrm{Cs}$, only critical thinking, problem solving, creativity, leadership, collaboration, communication, and use of ICT were cited among Korean definitions. Other skills such as innovation, cross-cultural understanding, and career and life skills were not present. The low representation of smart learner keywords across the

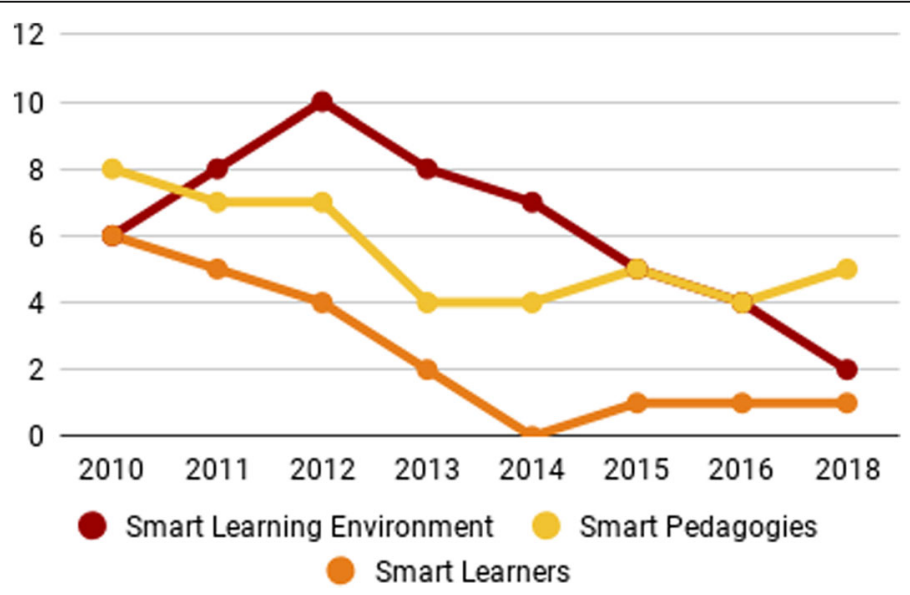

Fig. 2 Keyword frequency of smart learning elements from 2010 to 2018 
years is surprising because the smart learning initiative in Korea began with the learner in mind.

\section{Conceptual ambiguity lingers in the smart learning discourse}

In the literature section, we summarized that smart learning definitions vary in three perspectives, with the emphasis either being on technology, learners, or pedagogy. These varying perspectives are evidence of the conceptual ambiguity present in the global discourse of smart learning. Our analysis of the 62 definitions revealed that Korean scholars' discourse on smart learning shares similar patterns of such conceptual ambiguity for all three perspectives.

First, we observed that scholars were varied in their concept of smart learning technologies, defining it as either a 'learning system/environment' or a 'learning support system/service' (Fig. 3). More scholars (23 out of 62 definitions) defined smart learning in the perspective of a 'learning system/environment.' For example, Lee and Lee (2012) defined smart learning as "a customized intelligent learning system to strengthen learner's competency in the 21st century, which is to transform educational systems such as educational environment, educational contents, instructional methods, and assessment" (p. 148). We coded 'learning support system/service' separately because we believe the use of the keyword 'support' or 'service' presents a different concept, particularly in the scope and extent of how much a user (in this case, the learner) is expected to interact with the learning system. Support systems or services are often needs-based and regarded as optional or on-demand. Wang and Ng (2012) system criteria describe learner support as a feature where "learners can get adaptive learning assistance and guidance in the whole learning process, including FAQs, courseware usage, tips for learning, and access to experts' answers" (p. 156). While these two codes present some ambiguity in how the technology is conceptualized, the higher frequency of these codes imply that smart learning definitions still place a larger emphasis on the technology compared to pedagogy and learners.

Secondly, several Korean scholars were varied in their concept of smart pedagogy, explicitly defining smart learning as either a 'learning paradigm' or 'learning method.' We note that these two codes conceptually differ. Smart learning defined as a learning paradigm positions it as a learning theory for understanding how people learn, similar to behaviorism, cognitivism, constructivism, and connectivism. Under the umbrella of pedagogy, a paradigm is broader than a learning method, which in turn refers to specific ways of facilitating learning (Reigeluth 1999, preface). Several scholars described the smart learning method as a "smart way" (Kang 2011; Noh 2011) in their definitions. For example, Noh's (2011) definition states that "a smart way means customized, intelligent, convergent, social learning, and collective intelligence" (p. 23).

\section{Learning System/Environment 23 \\ Learning Method 12 \\ Learning Support System/Service 7 \\ Learning Paradigm 3}

Fig. 3 Varying concepts of smart learning environments and pedagogy 
Third, conceptual ambiguity is also found in Korean scholar's discussion on smart learners. Our analysis surfaced seven keywords on smart learners, all of which reflect the soft skills expected in the twenty-first century. However, a few scholars went beyond citing twenty-first century skills and enacted five new codes that describe a broader concept--the smart learning experience (Fig. 4). For example, Kwak (as cited in Lee et al. 2013) brought up the idea of making smart learning exciting and engaging, which considers the emotions and feelings of smart learners. In fact, Kwak (2010) was one of the earliest scholars contributing to the Korean smart learning discourse, but his ideas and definition did not proliferate. Two new concepts were also proposed by Kwon and Bhang (2012) who defined smart learning as an endeavor to enhance the effectiveness and efficiency of learning. Kwak (2010) and Kwon and Bhang (2012) align to the ideas proposed by Merrill (2012) who described smart learning environments to be effective, efficient, and engaging. Furthermore, KERIS' (as cited in Koo, 2012) defines smart learning as "a learning method which the learner develops self-initiated and creative learning capability while he/she utilizes smart devices and social networks to examine his/her needs and establish a learning process to achieve optimal results" (p. 161). KERIS' definition is one example which brings up additional considerations on the learner such as their actions, learning process, achievement, and outcomes.

The varying perspectives of technology, pedagogy, and learners seen in smart learning definitions confirm that there is conceptual ambiguity and uncertainty in how smart learning is understood and interpreted by Korean scholars. This problem is not a unique phenomenon in the Korean context, yet it is still noteworthy that such conceptual ambiguity was not readily resolved even with the leadership of the central government's smart learning initiative and policy statements.

Paths of discoursal development vary across the three domains of smart learning Our chronological analysis (Fig. 5a, b, c) revealed that the three elements of smart learning took a different path in their conceptual development over the years.

\section{Smart learning environments discourse}

Overall, Korean scholars' discourse on smart learning environments showed both conceptual diversity and a clear saturation process from 2010 to 2018. Their discourse included a wide variety of technology requirements and system features necessary for smart learning. Figure 5a, showing the eleven keywords' lifespan testifies to the long-lasting discoursal dynamics and conceptual consistency in the smart learning environment discourse. Most importantly, the discussion on smart learning environments exhibited conceptual convergence towards 2016 as evidenced in the

Learning achievement/outcomes 6

Effective 3

Efficient 1

Exciting 1

Engaging 1

Fig. 4 Varying concepts of smart learning experience 


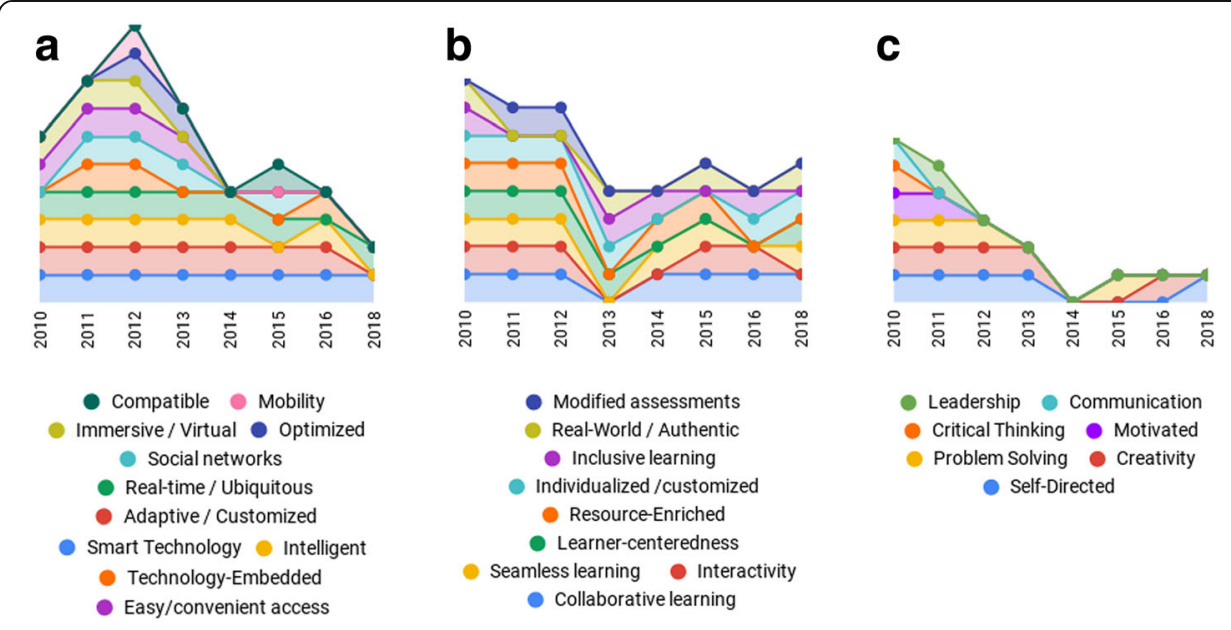

Fig. 5 a Smart learning environments: Keyword lifespan from 2010 to 2018. b Smart pedagogies: Keyword lifespan from 2010 to 2018. c Smart learners: Keyword lifespan from 2010 to 2018

saturated list of key-terms repeatedly appearing in publications. Starting from 2014, most scholars defined smart learning environments using following five keywords: smart technology, adaptive/customized, intelligent, real-time/ubiquitous, technology-embedded, and social networks.

The impact of government policy documents was most visible in this domain. The two keywords (adaptive and technology-embedded) appearing in the government acronym SMART influenced the discourse, particularly during the years such policies were published; though only the 'adaptive' keyword was consistently used in the discourse until 2017; the 'technology-embedded' keyword gradually decreased over time. This was partly because several other new keywords (e.g., mobility, intelligent) were introduced in the narratives of government policy documents (MEST 2011; MEST and KERIS 2011, 2012) and scholars (combine) had more choices in selecting smart environment-related terms from different parts of these documents. Overall, the use of the keywords from government policy documents was a common practice in the subsequent few years; early scholars of smart learning from 2010 were also seen to have strong influence throughout the discourse until 2016.

\section{Smart pedagogies discourse}

Korean scholars introduced and employed different ideas for smart pedagogy and vigorously engaged in a rich conceptual exploration throughout the years. Keywords related to smart pedagogy were saturated into nine broad instructional methods as codes, most having several sub-codes. The presence of many sub-codes indicates that smart learning scholars exhibited their conceptual creativity in defining instructional methods that they believed well-aligned with newly emerging learning paradigms such as constructivism and connectivism. The discourse on smart learning pedagogy was quite consistent from 2010 to 2012, then began to conceptually converge in 2015. Starting from 2015, scholars defined smart learning pedagogy using following five keywords: collaborative learning, interactivity, seamless learning, resource-enriched, real-world/authentic. Later scholars' definitions of smart pedagogy were still closely related to the ideas raised in 
early scholars' publications. Out of eight keywords found in the 2010 publications, five were repeated in the later scholar's publication in 2018.

In addition, the impact of government policy documents on this domain was very minimal. This is not surprising since none of the documents outlined specific pedagogy for smart learning. The only smart pedagogy concept included in the government acronym was related to resource-enriched content, which is often considered as another independent element of smart learning rather than part of smart pedagogy (Liu et al. 2017). Therefore, it is fair to conclude that Korean scholars' discussion on smart pedagogy proceeded on its own; rich conceptual exploration and consistency as well as discoursal robustness--as evidenced in the steady number of keywords remaining strong in later years--characterize this domain of the smart learning discourse.

\section{Smart learners discourse}

Our chronological analysis on the smart learners discourse yielded a result contrasting to the other two elements' paths of development. As shown in Fig. 5c, seven keywords emerged as smart learner codes, all of them appearing during the first 2 years, prior to the release of the government policy documents. Six keywords (self-directed, critical thinking, problem solving, motivated, creativity, communication) surfaced in 2011 and the last keyword, leadership, was first used in 2012. Despite this relatively robust start, the scholarly discussion on smart learners rapidly declined over the subsequent 8 years, especially around 2012. During the final 3 years, only one or two keywords sporadically appeared in publications showing the significant lack of attention and dwindling discussion on this vital element. It is important to note that the 2012 government document did present two smart learners keywords, motivated and self-directed. Yet, these did not trigger discussion among Korean scholars about smart learners. Overall, Korean scholars' smart learners discourse shows a highly fragile status, which might reflect the lack of attention given to learners and/or a broken conduit that should bring in a new conceptualization on smart learners.

\section{Discussion}

The smart learning "mix" is ambiguous

Smart learning provides a vision of a futuristic education. Glancing upon the broader discourse of smart learning, we observed that researchers have greatly attempted to explain the 'mix' of what smart learning is. There is a large number of scholarly definitions available and each is deliberate to infuse one or more of the following ideas on: (1) technology requirements and system features; (2) participants' roles, behaviors, and expectations; (3) pedagogical adaptations in instructional methods, content delivery, assessment, feedback, and learner support; (4) curricular goals. Not surprisingly, Korean scholars' smart learning discourse showed an intricate and complex relationship with the smart learning discourse carried out by the global and international community. While these themes are commonly shared across both, they also show that the discourse has not been centered on either one perspective of technology, pedagogy, or learners. Definitions are mixed, with varying perspectives and conceptual ambiguity. 


\section{Dominance of technology}

The dominating influence of technology as the driving force for smart learning is another common thread between the Korean scholars' discussion and international scholarly community. The discourse on the technology requirements (i.e., smart device, mobile devices, advanced ICT, computers, sensors, cloud computing, Internet, wireless networks, servers) and system features (i.e., intelligent, customized, adaptive, personalized, real-time/sensing, immersive, flexible, optimized, mobility, easy/convenient) that surfaced among Korean definitions closely aligned to the features and technology requirements identified by international scholars on smart learning environments over the years (Hwang 2014; Kinshuk et al. 2016; Klimova and Simonova 2015; Koper 2014; Raghunath et al. 2018; Tikhomirov et al. 2015; Yang et al. 2008; Zhu et al. 2011). However, the international discourse includes a broader scope of system features and requirements which Korean scholars have not yet identified such as context awareness, device and data security, big data and learning analytics, interoperability, pervasiveness, and self-directed guided systems that provide guidance, hints, and learning suggestions to help learners achieve learning goals (Hwang 2014; Kinshuk et al. 2016; Raghunath et al. 2018; Yang et al. 2008).

The ambiguity in defining smart learning environments as either a learning system or a learning support system is also common to both the Korean and international discourse, however, there are unique differences between the two. Our analysis shows that the Korean discourse implies a support structure that is pedagogical and teacher-initiated, while the international discourse suggests support structure that is more advanced and system-led. For example, Pyo et al. (2016), from the Korean discourse, proposes the idea of learning systems that can support collaboration and interaction between teachers and students. In such systems, the support structure implied is simpler, pedagogical, and teacher-led. On the other hand, Kinshuk et al. (2016) and Hwang (2014) from the international discourse suggest systems that have supportive tools built-in that can provide hints and learning suggestions, so learners are guided to do the right thing, in the right way, at the right time, and the right place, based on their needs. Systems that have "smart support" can adapt, sense, infer, learn, anticipate, and self-organize based on student patterns of use (Uskov et al. 2015). Brusilovsky et al. (2014) describes systems that can provide visualization tools, automatic assessment tools, simulation tools, and problem-solving support tools. The influence of computing theories from artificial intelligence, intelligent tutoring systems, and human-computer interaction is more prominent in the international views of smart learning support systems than in Korea.

\section{Universal pedagogical concepts}

The pedagogies that surfaced in this study (e.g., collaborative learning, learner-centeredness, seamless learning, individualized learning, inclusive learning, authentic learning) among Korean scholars presented a rich discussion of instructional methods for smart learning. Among the three elements of smart learning, pedagogies were the least discussed element in government policy documents. This required scholars to explore and identify pedagogical approaches that they believe would fit the "mix" of smart learning. 
However, the list that surfaced in our study (Fig. 1) did not highlight any specific "new" pedagogy unique to the Korean discourse that was not already existing in the global discourse; pedagogical approaches among Korean scholars highly overlap with universal concepts of pedagogy. In fact, it seemed that Korean scholars selectively imported a few concepts from the international smart learning community. For example, the idea of 'seamless learning' was consistently included in Korean's scholars' discussion (e.g., Han et al. 2014; Jang 2014; Lim 2011). Seamless learning, as a concept, is widely circulated in the international smart learning scholarly community (e.g., Chiou et al. 2015; Kinshuk et al. 2016) and is related to other pedagogies such as formal and informal learning, flipped classrooms, BYOD, differentiated instruction, authentic learning, collaborative learning, and social learning. A unique lens from the international discourse proposed by Kinshuk et al. (2016) is to enable the fusion of technology and pedagogy in smart learning environments. Perhaps this would then call for more exploration, innovation, and creativity in the pedagogical concepts that fit the "mix" of smart learning.

\section{Unpacking smart learners further}

The elements of smart learning are impossible without each other (Tikhomirov et al. 2015). However, with the strong dominance of technology seen in smart learning trends, scholars have yet to deeply unpacked the element of the "smart learner." Scholars from both the Korean and international community have emphasized that smart learning puts the learner at the center (Kwak 2010; Zhu et al. 2016) and that the technology element is just a tool to: (1) help learners achieve greater outcomes (Tikhomirov et al. 2015), (2) satisfy learners' needs and goals (Klimova 2015) (3) help learners acquire and develop skills that prepare them to live and work in the twenty-first century (MEST and KERIS 2011), and (4) improve learning quality (Duran-Sanchez et al. 2018). While these key ideas have been mentioned in the literature, the influence has not been strong enough to sway the perspective away from the technology element. What has been widely discussed among scholars is the need for twenty-first century learners with twenty-first century skills. Both Korean and international scholars share the overall goal of developing twenty-first century skill sets such as collaboration, communication, critical thinking, and creativity. However, this is just one of the four areas that need further exploration.

\section{Limitations}

Despite our careful planning and analysis, this study poses several limitations. Firstly, the study analyzed texts written in two different languages, English and Korean, and the issues of mistranslation and misinterpretation were inherently present throughout the data collection and analysis process. Furthermore, varied academic practices, especially different citation and referencing conventions between Western and Korean scholarly publications made it very challenging for us to neatly streamline the database. We addressed this problem by establishing clear inclusion/exclusion criteria and team-based decision making, yet we acknowledge that our sampling and screening process might have missed or eliminated some scholarly publications that were critical to understanding the conceptual development of smart learning in Korean context. 
Secondly, we would like to mention that our study was primarily a semantic analysis of "smart learning" based on Korean scholarly publications. As a result, our analysis did not properly examine the contextual and cultural aspects of the discourse despite the fact that is reasonable to postulate that Korea's unique cultural and educational context must have shaped the scope and direction of the smart learning discourse in one way or another. Based on this limitation, we strongly recommend future research closely examine the linkage and dynamics between Korea's cultural and educational context and the conceptual evolvement of smart learning.

\section{Implications}

Our study offers important implications for various stakeholders, such as teacher practitioners, policy makers (e.g., government officials), and researchers involved in smart learning initiatives. South Korea's smart learning framework encourages technology to be well integrated into the student learning experience, which requires rethinking the pedagogical workflow. Smart learning implementation is not possible without the strong participation of teacher practitioners. In this light, we call for more active contributions from teacher practitioners to test the validity, productivity, usability, and usefulness of smart learning environments and the relevance of pedagogical approaches proposed by scholars.

As the smart learning discourse is dwindling, we suggest that policy makers find a new way to rekindle the discussion. One possible strategy is proactively inviting the voices of teachers to expand pedagogical concepts for smart learning. Teachers who have day-to-day interactions with students, potentially "smart learners," could lead rich discussions on conceptualizing how the fusion of smart learning environments and modern pedagogies could help learners: identify learning goals, manage their learning process, acquire skills and competencies for the twenty-first century, utilize learning systems effectively and efficiently, and most importantly, achieve greater learning outcomes.

While it is ideal to consult technology experts for the development of advanced smart learning systems, we recommend that teachers be included in these conversations to provide a more authentic view of the types of support students need, within the context of where their learners are situated. Furthermore, we encourage researchers to critically examine the existing three elements of smart learning (learning environments, pedagogies, and learners), and evaluate if another concept, such as "smart learning experience," can better serve as an overarching element to further develop the idea of smart learning that is more effective, engaging, and exciting to the new generation of young students.

\footnotetext{
Abbreviations

IASLE: International Association for Smart Learning Environments; KERIS: Korea Education and Research Information Service; MEST: Korea Ministry of Education, Science and Technology; P21: Partnership for twenty-first century skills
}

Availability of data and materials

The datasets used and/or analyzed during the current study are available from the corresponding author on reasonable request.

Authors' contributions

KB contributed to the introduction, literature review, theoretical framework, data collection, data analysis, reporting of results, discussion, and implications sections. YJ contributed to the introduction, literature review, data collection, data analysis, and reporting of results. JHL served as a qualitative methodology expert; contributed to the introduction, theoretical framework, data collection, data analysis, reporting of results, discussion, and implications sections. All authors read and approved the final manuscript. 


\section{Publisher's Note}

Springer Nature remains neutral with regard to jurisdictional claims in published maps and institutional affiliations.

\section{Author details}

${ }^{1}$ Center for Teaching and Learning, University of North Carolina at Charlotte, 9201 University City Blvd, Charlotte, NC 28223, USA. ${ }^{2}$ University of North Carolina at Charlotte, 9201 University City Blvd, Charlotte, NC 28223, USA.

Received: 13 July 2018 Accepted: 11 September 2018

Published online: 10 October 2018

\section{References}

IASLE. (2018). Background: Smart learning. Retrieved July 9, 2018, from http://iasle.net/about-us/background/

S.H. Bang, A study on strategies of self-directed learning to promote smart learning. Journal of Lifelong Learning Society 8(1), 93-112 (2012) http://uci.or.kr/G704-SER000015054.2012.8.1.003

P. Brusilovsky, S. Edwards, A. Kumar, L. Malmi, L. Benotti, D. Buck, S. Sosnovsky. (2014). Increasing adoption of smart learning content for computer science education (pp. 31-57). Presented at the Proceedings of the Working Group Reports of the 2014 on Innovation \& Technology in Computer Science Education Conference, ACM

S.-F. Chiou, H.-C. Su, K.F. Liu, H.F. Hwang, Flipped classroom: A new teaching strategy for integrating information technology into nursing education. Hu Li Za Zhi 62(3), 5-10 (2015)

J.-H. Cho, A study on the factors influencing the satisfaction and effectiveness of smart learning in the view of HRD in company. Journal of the Korea Academia-Industrial Corporation Society 19(3), 468-478 (2018)

W. Derzko, (2006). Smart Technologies in the New Smart Economy (Vol. 1, p. 2006). Presented at the 1st Technology Futures Forum (TFF) VIT Valimo (Metallimiehenkuja 2), Otaniemi, Espoo, Finland

A. Duran-Sanchez, J. Alvarez-Garcia, M. Del Rio-Rama, C. de la, \& O. Sarango-Lalangui. (2017). Analysis of the scientific literature published on smart learning. Espacios, 39(10). Retrieved from https://www.researchgate.net/profile/Jose_ Alvarez_Garcia/publication/323827346_Analysis_of_the_Scientific_Literature_Published_on_Smart_Learning/links/ 5aacfb5c0f7e9b4897bd2cab/Analysis-of-the-Scientific-Literature-Published-on-Smart-Learning.pdf

M. S. Gallagher, (2016). Charting Trajectories on the Peripheries of Community Practice: Mobile Learning for the Humanities in South Korea (Dissertation)

J. Gikas, M.M. Grant, Mobile computing devices in higher education: Student perspectives on learning with cellphones, smartphones \& social media. Internet High. Educ. 19, 18-26 (2013). https://doi.org/10.1016/j.iheduc.2013.06.002

C. Gordon, Addressing Security Risks for Mobile Devices: What Higher Education Leaders Should Know (Dissertation) (Theses, Dissertations, and Student Research, Educational Administration, 2015) Retrieved from https://digitalcommons.unl.edu/ cehsedaddiss/248

B. Gros, The design of smart educational environments. Smart Learning Environments 3(1), 15 (2016) https://doi.org/10.1186/ s40561-016-0039-x

S.-J. Han, H.-S. Kim, G. Heo, A meta-analysis on the effectiveness of smart-learning. Journal of Fisheries and Marine Sciences Education 26(1), 148-155 (2014). https://doi.org/10.13000/JFMSE.2014.26.1.148

J. Hardison, (2013). Part 1: 44 smart ways to use smartphones in class. Retrieved August 28, 2016, from http://gettingsmart. com/2013/01/part-1-44-smart-ways-to-use-smartphones-in-class/

T. Hoel, J. Mason, Standards for smart education - Towards a development framework. Smart Learning Environments 5(3) (2018). https://doi.org/10.1186/s40561-018-0052-3

E. Horowitz, (2015). A peek at a 'smart' classroom powered by the internet of things. Retrieved August 5, 2016, from https://www.edsurge.com/news/2015-08-11-a-peek-at-a-smart-classroom-powered-by-the-internet-of-things

H.F. Hsieh, S.E. Shannon, Three approaches to qualitative content analysis. Qual. Health Res. 15(9), 1277-1288 (2005). https://doi.org/10.1177/1049732305276687

M.T.A. Hua, Promises and threats: iN2015 masterplan to pervasive computing in Singapore. Science, Technology and Society 17(1), 35-56 (2012) https://doi.org/10.1177/097172181101700103

D.J. Hwang, Smart innovation in education and learning. Presented at the International E-Learning Conference (IEC2011), Muang Thong Thani. (2011). Retrieved from alternative URL: https://www.thaicyberu.go.th/node/14528

G.-J. Hwang, Definition, framework and research issues of smart learning environments - a context-aware ubiquitous learning perspective. Smart Learning Environments 1(1), 4 (2014) https://doi.org/10.1186/s40561-014-0004-5

G.-J. Hwang, C.-C. Tsai, S.J.H. Yang, Criteria, strategies and research issues of context-aware ubiquitous learning. J. Educ. Technol. Soc. 11(2), 81-91 (2008)

Y. Hwang, Y. Jin, C. Shim, K. Choi, K. Kim, Study on history class design using GBS under smart learning environment. The Korean Journal of the Learning Sciences 5(1), 57-81 (2011)

P. Hyun, Forefront of smart education, Sejong. Retrieved September 24, 3018. (2015). from http://www.korea.net/NewsFocus/ Sci-Tech/view?articleld $=127152$

ITU, Measuring the Information Society Report 2017 (Volume 1) (International Telecommunications Union, Geneva, Switzerland, 2017) Retrieved from https://www.itu.int/en/TU-D/Statistics/Documents/publications/misr2017/MISR2017_Volume1.pdf

S. Jang, (2010, December). Education 3.0 and smart learning. Powerpoint presented at the Educational Information Forum, Korea Education and Research Information Service

S. Jang, Study on service models of digital textbooks in cloud computing environment for SMART education. International Journal of U- and e-Service, Science and Technology 7(1), 73082 (2014)

J. Jo, J. Park, H. Ji, Y. Yang, H. Lim, A study on factor analysis to support knowledge based decisions for a smart class. Information Technology and Management 17(1), 43-56 (2016) https://doi.org/10.1007/s10799-015-0222-8

J. Jo, Y. Yang, H. Lim, in Computer Science and its Applications. Lecture Notes in Electrical Engineering 203, ed. by S. Yes, Y. Pan, Y. Lee, H. Chang. Design of a structured plug-in smart education system, vol 203 (Springer. Retrieved from, Dordrecht, 2012), pp. 891-901. https://link-springer-com.librarylink.uncc.edu/chapter/10.1007/978-94-007-5699-1_91

D.H. Jonassen, C. Carr, H.P. Yueh, Computers as mindtools for engaging learners in critical thinking. TechTrends 43(2), 24-32 (1998). https://doi.org/10.1007/BF02818172 
I. Kang, B. Lim, J. Park, Exploring the theoretical framework and teaching \& learning strategies of smart learning: Using cases of university classrooms. The Korean Journal of Educational Methodology Studies 24(2), 283-303 (2012)

J.-H. Kang, A study on utilizing SNS to vitalize smart learning. Journal of Digital Convergence 9(5), 265-274 (2011)

KERIS. (2011). Guideline for smart education contents quality management (no. Rm 2011-13). Korea Education and Research Information Service (KERIS)

M. Kim, A study on educational application of smart devices for enhancing the effectiveness of problem solving learning. Journal of Korean Society for Internet Information 15(1), 143-156 (2014). https://doi.org/10.7472/jksii.2014.15.1.143

M. Kim, Y. Bae, Development of a smart education model for field application of smart education. Journal of Internet Computing and Services 13(5), 77-92 (2012)

S. Kim, S.-M. Song, Y.-I. Yoon, Smart learning services based on smart cloud computing. Sensors 11(8), 7835-7850 (2011)

S.M. Kim, Along with e-learning and cloud computing, comes the advancement of smart learning: EBS, the heart of smart learning and lifelong education. Korea IT Times 91, 18-20 (2012)

T. Kim, J.Y. Cho, B.G. Lee, in Open and Social Technologies for Networked Learning, ed. by T. Ley, M. Ruohonen, M. Laanpere, A. Tatnall. Evolution to smart learning in public education: A case study of korean public education, vol 395 (Springer Berlin Heidelberg. Retrieved from, Berlin, Heidelberg, 2013), pp. 170-178. http://link.springer.com/10.1007/978-3-642-37285-8_18

N.-S. Kinshuk, I.-L. Chen, S.W. Cheng, Chew, Evolution is not enough: Revolutionizing current learning environments to smart learning environments. International Journal of Artificial Intelligence in Education 26(2), 561-581 (2016). https://doi.org/ 10.1007/s40593-016-0108-x

KISA, in Jeolanam-do. 2017 survey on internet usage (Korea Internet \& Security Agency, Korea, 2018) Retrieved from http://isis. kisa.or.kr/board/fileDown.jsp?pageld=060300\&bbsld=10\&itemld=356\&athSeq=1

B. Klimova, (2015) Assessment in Smart Learning Environment - A Case Study Approach. Smart Education and Smart e-Learning. Smart Innovation, Systems and Technologies, vol 41. Springer, Cham. https://doi.org/10.1007/978-3-31919875-0_2.

B. Klimova, I. Simonova, in Smart Education and Smart e-Learning, ed. by V. L. Uskov, R. J. Howlett, L. C. Jain. Study materials in smart learning environment - A comparative study, vol 41 (Springer, Cham, Switzerland, 2015), pp. 81-90 https://doi.org/ 10.1007/978-3-319-19875-0_8

D.-H. Koo, Trends and revitalization of smart-learning in elementary and middle schools. Asian Journal of Information Technology 11(5), 160-168 (2012) https://doi.org/10.3923/ajit.2012.160.168

R. Koper, Conditions for effective smart learning environments. Smart Learning Environments 1(5), 1-17 (2014) https://doi. org/10.1186/s40561-014-0005-4

D.-H. Kwak, (2010). Meaning and Prospect for Smart Learning. In Proceedings from the seminar for Korea e-learning industry association

H.I. Kwon, D.-J. Kim, G.-J. Ryu, J.-H. Kang, J.-S. Park, H.-Y. Joo, The Framework of the Smart Learning Infrastructure in South Korea-Focus on Agriculture Education System. In Free and Open Source Software Conference (FOSSC-13), 18-19 (2013) http://fossc.om/images/papers/Hyeog_In_Kwon_Fossc_Oman_2013.pdf

S. Kwon, S. Bhang, Changes to the educational paradigm and smart learning: How shall we view them? Journal of Lifelong Learning Society 8(31), 53-60 (2012)

A. J. Lee, (n.d.). Smart Learning in Korea

B. Lee, 글로벌 시대를 선도할 한국의 스마트러닝 산업 정책방향. Korea Information Processing Society Review 20(5), 4-5 (2013b)

D.-W. Lee, S.-H. Lee, The future of ICT fusions based on smart technology. Journal of Digital Convergence 10(2), 147-152 (2012)

J. Jo, K. Park, D. Lee, \& H.Lim, (2014). An integrated teaching and learning assistance system meeting requirements for smart education. Wireless personal communications, 79(4), 2453-2467.

J. Lee, H. Zo, H. Lee, Smart learning adoption in employees and HRD managers. Br. J. Educ. Technol. 45(6), 1082-1096 (2014)

J.A. Lee, T.H. Kim, J.H. Chung, Study on communication of characteristics smart learning from UX perspective. International Journal of Smart Home 7(6), 59-72 (2013)

J.E. Lee, S.M. Jin, Implementation of smart learning model for improving digital communication competencies of middle aged. The Journal of the Korea Contents Association 14(4), 522-533 (2014). https://doi.org/10.5392/JKCA.2014.14.04.522

J.E. Lee, D. Lim, G. Um, A cyber engineering education strategy based on smart learning. Information 18(4), 1169-1174 (2015)

M.-S. Lee, Y.-E. Son, Development of BYOD strategy learning system with smart learning supporting. International Journal of Software Engineering and Its Applications 7(3), 259-268 (2013)

S.-G. Lee, A study on the development of instructional model for smart learning in the school library. Journal of Korean Library and Information Science Society 44(2), 27-50 (2013a) https://doi.org/10.16981/kliss.44.2.201306.27

V.S. Lee, in A Guide to Faculty Development, 2nd edn., ed. by K. J. Gillespie, D. L. Robertson. Program types and prototypes (Jossey-Bass, San Francisco, CA, 2010), pp. 21-34

J. Leem, B. Lim, E. Sung, Developmental Study on the Quality Certification Standards of Smart Education Contents. Journal of Korean Association for Educational Information and Media 20(3), 327-353 (2014) http://uci.or.kr/G704-000750.2014.20.3.002

J.-H. Leem, S.H. Kim, Effects of individual learning and collaborative learning on academic achievement, self-directed learning skills and social efficacy in smart learning. Journal of Korean Association for Educational Information and Media 19(1), 1-24 (2013)

K. Lim, Research on developing instructional design models for enhancing smart learning. The Journal of Korean Association of Computer Education 14(2), 33-45 (2011)

Lim, K. (2012, October). "SMART" learning trends in Korea. Presented at the innovative ICT practices in teaching and learning: A regional seminar, Sejong Hotel, Seoul, Korea. Retrieved from http://www.unescobkk.org/fileadmin/user_upload/ict/ Workshops/regionalseminar2012/ppt/Keol_Lim_SK_Telecom.pdf

D. Liu, R. Huang, M. Wosinski, in Smart Learning in Smart Cities. Characteristics and framework of smart learning (Springer Nature, Singapore, 2017), pp. 31-48 https://doi.org/10.1007/978-981-10-4343-7_3

C. McLoughlin, M.J.W. Lee, The three P's of pedagogy for the networked society: Personalization, participation, and productivity. International Journal of Teaching and Learning in Higher Education 20(1), 10-27 (2008)

M.D. Merrill, First Principles of Instruction (John Wiley \& Sons, San Francisco, 2012) 
MEST, Smart Education Strategy Implementation Plan (Ministry of Education, Science and Technology, Seoul, Korea, 2011) Retrieved from http://www.moe.go.kr/boardCnts/fileDown.do?m=05\&s=moe\&fileSeq=f82c54c8f759324e8a36b73084e56a22

MEST, \& KERIS. (2011). Adapting education to the information age (No. PM 2011-1). Seoul, Korea: Korea Education and Research Information Service (KERIS). Retrieved from http://english.keris.or.kr/whitepaper/WhitePaper_eng_2011_ wpap.pdf

MEST, \& KERIS. (2012). Adapting education to the information age (No. PM 2012-3). Seoul, Korea: Korea Education and Research Information Service (KERIS). Retrieved from http://english.keris.or.kr/whitepaper/WhitePaper_eng_2012.pdf

Metiri Group, NCREL, enGauge 21st Century Skills for 21st Century Learners (North Central Regional Educational Laboratory, Chicago, IL, 2003)

C. Nerantzi, S. Beckingham, in Lifewide Learning \& Education in Universities and Colleges E-Book, ed. by N. Jackson, J. Willis. BYOD4L - Our open magical box to enhance individuals' learning ecologies (Lifewide Education. Retrieved from, UK, 2014) http://www.learninglives.co.uk/e-book.html

W. Ng, in New Digital Technology in Education: Conceptualizing Professional Learning for Educators, ed. by W. Ng. Mobile learning: BYOD and personalised learning (Springer International Publishing, Cham, 2015), pp. 171-189 Retrieved from https://doi.org/10.1007/978-3-319-05822-1_8

K.-S. Noh, in Korea Education and Research Information Service. Smart learning and future education. Presented at the education information Wednesday forum (2011, May)

K.-S. Noh, S.-H. Ju, J.-T. Jung, An exploratory study on concept and realization conditions of smart learning. Journal of Digital Convergence 9(2), 79-88 (2011)

OECD. (2018). Internet access (indicator). Retrieved from https://www.oecd-ilibrary.org/content/data/69c2b997-en

E.-T. Ong, in Presented at the 10th UNESCO-APEID International Conference on Education. The Malaysian smart schools project: An innovation to address sustainability (Thailand, Bangkok, 2006) Retrieved from http://www.teo-education.com/ teophotos/albums/userpics/ong_6B.doc

P21. (2007). Framework for 21st Century Learning. Retrieved July 10, 2018, from http://www.p21.org/our-work/p21-framework

N. Parmar, (2016). 3 tips for mobile pedagogy in the classroom. Retrieved August 28, 2016, from http://asia.blog.terrapinn. com/edutech/2016/06/10/223/?utm_campaign=8603\%20EduTECH\%20Asia\%202016\%20-\%20Blog\%20Newsletter\%20\%20June\%2013_NON\%20SG\&utm_medium=email\&utm_source=Eloqua

C.-K. Pyo, K.-S. Han, G.-S. Ryu, An empirical study on the factors influencing user satisfaction of military smart-education. Journal of Digital Convergence 14(2), 41-48 (2016)

R. Raghunath, C. Anker, A. Nortcliffe, Are academics ready for smart learning? Br. J. Educ. Technol. 49(1), 182-197 (2018). https://doi.org/10.1111/bjet.12532

C. Redecker, Y. Punie, The future of learning 2025: Developing a vision for change. Future Learning 2(1), 3-17 (2013)

C. M. Reigeluth (ed.), Instructional-Design Theories and Models: A New Paradigm of Instructional Theory, vol 2 (Lawrence Erlbaum Associates, Inc., Mahwah, NJ, 1999)

S.-O. Roh, Y.-G. Woo, The status and future agenda of smart learning support policies for students with disabilities of Korea. Journal of Special Children Education 18(4), 201-225 (2016). https://doi.org/10.21075/kacsn.2016.18.4.201

H.-K. Shin, Y. Kim, A study on the factors affecting smart learning-focusing on the moderating effect of learning time. Journal of the Korea Industrial Information Systems Research 16(5), 93-105 (2011)

Statista, in From. Internet usage in South Korea. Retrieved July 11, 2018 (2016) https://www.statista.com/topics/2230/internetusage-in-south-korea/

M. Sung, A study of adults' perception and needs for smart learning. Procedia Soc. Behav. Sci. 191, 115-120 (2015)

M. Swallow, The year-two decline: Exploring the incremental experiences of a 1:1 technology initiative. J. Res. Technol. Educ. 47(2), 122-137 (2015)

V. Tikhomirov, N. Dneprovskaya, E. Yankovskaya, in Smart Education and Smart e-Learning, ed. by V. L. Uskov, R. J. Howlett, L. C. Jain. Three dimensions of smart education, vol 41 (Springer, Cham, Switzerland, 2015), pp. 47-56 https://doi.org/10. 1007/978-3-319-19875-0_5

V.L. Uskov, J.P. Bakken, A. Pandey, in Smart Education and Smart e-Learning, ed. by V. L. Uskov, R. J. Howlett, L. C. Jain. The ontology of next generation smart classrooms, vol 41 (Springer, Cham, Switzerland, 2015), pp. 3-14 https://doi.org/10. 1007/978-3-319-19875-0_1

A. Uzelac, N. Gligoric, S. Krco, A comprehensive study of parameters in physical environment that impact students' focus during lecture using internet of things. Comput. Hum. Behav. 53, 427-434 (2015). https://doi.org/10.1016/j. chb.2015.07.023

M. Wang, \& J. W. Ng, (2012). Intelligent mobile cloud education: smart anytime-anywhere learning for the next generation campus environment (pp. 149-156). Presented at the Intelligent Environments (IE), 2012 8th International Conference on, IEEE. https://doi.org/10.1109/IE.2012.8

S.J.H. Yang, T. Okamoto, S.-S. Tseng, Context-aware and ubiquitous learning (guest editorial). Educational Technology \& Society 11(2), 1-2 (2008)

E. Zhu, M. Kaplan, R. C. Dershimer, \& I. Bergom, (2011). Use of laptops in the classroom: Research and best practices (No. Occasional Paper No. 30). Center for Research on Learning and Teaching (CRLT), University of Michigan. Retrieved from https://eric.ed.gov/?id=ED573973

Z.-T. Zhu, B. He, Smart education: New frontier of educational informatization. E-Education Research 12, 1-13 (2012)

Z.-T. Zhu, M.-H. Yu, P. Riezebos, A research framework of smart education. Smart Learning Environments 3(1) (2016). https:// doi.org/10.1186/s40561-016-0026-2 